\title{
Prevalência da mucosite oral em pacientes portadores de câncer de cabeça e pescoço atendidos na Unidade de Alta Complexidade em Oncologia (UNACON) - Feira de Santana, BA, no período de 2015
}

\author{
$\underline{\text { Vinicius Silva Bastos de Jesus }}^{1}$; Márcio Campos Oliveira²; Agda Braga Teixeira3 ${ }^{3}$; Ana Paula \\ Eufrázio do Nascimento Andrade ${ }^{4}$ \\ 1- Bolsista PROBIC/UEFS, graduando em odontologia, Universidade Estadual de Feira de Santana, e-mail: \\ viniumbivis@gmail.com. \\ 2- Orientador, Departamento de saúde, Universidade Estadual de Feira de Santana, email: \\ marciopatologiaoral@gmail.com \\ 3- Participante do NUCAO, graduanda em odontologia, Universidade Estadual de Feira de Santana, email: \\ agda braga@hotmail.com \\ 4- Mestranda em saúde coletiva, Universidade Estadual de Feira de Santana, email: apeufrazio@gmail.com
}

PALAVRAS-CHAVE: Câncer de cabeça e pescoço; mucosite oral; radioterapia.

\section{INTRODUÇÃO}

O estágio em que é detectado o tumor maligno tem implicações diretamente proporcionais nos seus prognóstico e tratamento, cujas modalidades mais comumente empregadas são a cirurgia, a radioterapia e a quimioterapia, com ou sem associação entre elas. A oncoterapia, por sua vez, provoca numerosos efeitos colaterais, dos quais vários se manifestam na cavidade oral ${ }^{1 ; 2}$. A radioterapia (RT) em região de cabeça e pescoço é grande promotora dessas complicações, tanto durante quanto após o tratamento, sobretudo na mucosa oral e nas glândulas salivares, resultando em mucosite oral $(\mathrm{MO})$ e xerostomia, mais agravadas quando a RT é associada à quimioterapia (QT) ${ }^{3 ; 4}$.

A MO é uma reação inflamatória aguda, caracterizada por eritema e edema na mucosa oral, que podem resultar em ulcerações. Sua ocorrência varia de 90 a $97 \%$ nos pacientes com câncer de cabeça e pescoço tratados com RT ${ }^{5 ; 6}$. É observada clinicamente após a $2^{\circ}$ ou $3^{\mathrm{a}}$ semana do início do tratamento. $\mathrm{O}$ processo inflamatório inicial predispõe a mucosa a invasões bacterianas oportunistas, que conforme a intensidade podem evoluir para a formação de úlcera ${ }^{7 ; 8}$. Fatores relacionados à modalidade terapêutica, ao tipo de radiação, ao uso e tipo de fármaco, provocam efeitos sobre os tecidos normais, e quando associados ao uso do tabaco, consumo de álcool, à presença de comorbidades crônico-degenerativas, a idade e a condição de higiene e saúde bucal do paciente, podem potencializar essas manifestações em nível de mucosa oral ${ }^{8}$.

\section{MATERIAIS E MÉTODOS}

Através da coleta de dados secundários através de prontuários, foram incluídos na pesquisa todos os prontuários dos pacientes de câncer de cabeça e pescoço atendidos na UNACON em 2015 que tiverem idade igual ou superior a 18 anos de idade. No entanto, foram excluídos do estudo os prontuários que não foram preenchidos na íntegra, ou que eram de pacientes não portadores de câncer de cabeça e pescoço, ou com idade menor que 18 anos. Coletou-se dados socioeconômicos (sexo, idade, cor de pele, naturalidade, habitação, profissão, etilismo e tabagismo); relacionados à patologia (tipo histológico, estádio clínico, localização do tumor, tipo de tratamento, quimioterápicos, número de ciclos de quimioterapia, 
intervalo entre os ciclos, medicamentos de uso contínuo, suspensão do tratamento e relato de mucosite). O número do parecer de aprovação do comitê de ética é 087/2008.

\section{RESULTADOS ALCANÇADOS E DISCUSSÃO}

Entre 62 pacientes que tiveram sua história oncológica analisada e que realizaram tratamento radioterápico seja de forma isolada, adjuvante ou concomitante a QT, diagnosticou-se a mucosite oral em 61,7\% (37/60). Dos casos encontrados, 31,3\% (10/32) exibiu mucosite de grau $1 ; 65,6 \%(21 / 32)$ de grau 2 e $3,1 \%(1 / 32)$ de grau 3 ; sendo que a $12^{\mathrm{a}}$ sessão da radioterapia foi a de surgimento mais comum dessa lesão.

Participaram da coleta 45 homens $(72,6 \%)$ e 17 mulheres $(27,4 \%)$, de cor da pele prevalentemente parda (47,5\% - 29/61), mais frequente entre 61 e 80 anos (44,3\% - 27/61), naturais de Feira de Santana (26,8\% - 15/56) e que habitam a zona urbana (77,4\% - 48/62). Os pacientes foram acolhidos pelo Sistema Único de Saúde (SUS) em sua maioria $(95,2 \%$ 59/62).

Quanto à profissão, eram predominantemente aposentados $(48,2 \%$ - 27/56) ou lavradores $(14,3 \%$ - 8/56). Não houve informações suficientes em prontuários para se determinar a prevalência de renda.

Em sua maioria eram pacientes etilistas $(73 \%$ - 43/59) e tabagistas $(82,3 \%$ - 50/60).

Seguem os resultados de pacientes em tratamento oncológico com relato de mucosite segundo tipo histológico.

\begin{tabular}{lcc} 
Tipo histológico & $\mathbf{n}$ & $\%$ \\
CEC & $\mathbf{3 2}$ & $\mathbf{8 6 , 5 \%}$ \\
Sim & $\mathbf{2 1}$ & $\mathbf{9 1 , 3 \%}$ \\
Não & $\mathbf{5 3}$ & $\mathbf{8 8 , 3 \%}$ \\
Total & & \\
Células acinares & & $\mathbf{5 , 4 \%}$ \\
Sim & $\mathbf{2}$ & $\mathbf{0 \%}$ \\
Não & $\mathbf{0}$ & $\mathbf{3 , 3 \%}$ \\
Total & $\mathbf{2}$ & \\
Linfoma de Hodgkin & & $\mathbf{1 , 7 \%}$ \\
Sim & & $\mathbf{0 \%}$ \\
Não & $\mathbf{1}$ & $\mathbf{0}$ \\
Total & $\mathbf{1}$ & \\
& & \\
\hline
\end{tabular}




$\begin{array}{lcc}\text { Linfoma não Hodgkin } & \mathbf{0} & \\ \text { Sim } & \mathbf{0 \%} \\ \text { Não } & \mathbf{1} & \mathbf{4 , 3 \%} \\ \text { Total } & & \mathbf{1 , 7 \%} \\ \text { Outro } & \mathbf{2} & \\ \text { Sim } & \mathbf{1} & \mathbf{5 4 \%} \\ \text { Não } & \mathbf{3} & \mathbf{4 , 3 \%} \\ \text { Total } & & \mathbf{5 \%} \\ \text { Total } & & \\ \text { Sim } & \mathbf{3 7} & \mathbf{1 0 0 \%} \\ \text { Não } & \mathbf{2 3} & \mathbf{1 0 0 \%} \\ \text { Total } & \mathbf{6 0} & \mathbf{1 0 0 \%}\end{array}$

TABELA 1: Distribuição do número (n) e percentual (\%) dos casos de pacientes portadores de câncer de cabeça e pescoço com relato de mucosite oral atendidos na UNACON em Feira de Santana, segundo tipo histológico, UNACON, 2015.

\section{CONCLUSÃO}

A mucosite oral foi identificada em $61,7 \%$ dos pacientes, de grau predominante II, atendidos na Unidade de Alta Complexidade em Oncologia (UNACON), em Feira de Santana - Bahia, no período de 2015, que tiveram história oncológica analisada. Predominaram os casos de mucosite oral em homens, pardos, entre 61 e 80 anos, naturais de Feira de SantanaBA, habitantes da zona urbana. Durante o tratamento, ocorreram reações de toxicidade que, em maior frequência, não acarretaram interrupção do tratamento.

\section{REFERÊNCIAS}

1. FREITAS, D. A. et al. Sequelas bucais da radioterapia de cabeça e pescoço. Rev. $\boldsymbol{C E F A C}$ [online]., v.13, n.6, p. 1103-1108, 2011. ISSN 1982-0216. Disponível em:< http://www.scielo.br/pdf/rcefac/v13n6/161-10.pdf>. Acesso em 22 set 2014.

2. VOlPATO, L. E. R. et al. Mucosite bucal rádio e quimioinduzida. Rev. Bras. Otorrinolaringol. [online]., v.73, n.4, p. 562-568, 2007. ISSN 0034-7299. Disponível em:< http://www.scielo.br/pdf/rboto/v73n4/a17v73n4.pdf $>$. Acesso em 26 Set 2014.

3. LOPES, C. O; MAS, J. R. I; ZANGARO, R. A. Prevenção da xerostomia e da mucosite oral induzidas por radioterapia com uso do laser de baixa potência. Radiol Bras [online]., v.39, n.2, p. 131-136, 2006. ISSN 0100-3984. Disponível em:< http://www.scielo.br/pdf/rb/v39n2/29196.pdf>. Acesso em 26 set 2014. 
4. SAWADA, N.O. et al. Quality of life evaluation in cancer patients to submitted to chemotherapy. Rev Esc Enferm USP [Internet], v.43, n. 3, p. 581-7, 2009. Disponível em<: htt p://www.scielo.br/pdf/reeusp/v43n3/en_a12v43n3.pdf>. Acesso em 18 out. 2014.

5. FIGUEIREDO, A. L. P. et al. Laser terapia no controle da mucosite oral: um estudo de metanálise. Rev. Assoc. Med. Bras. [online]., v.59, n.5, p. 467-474, 2013. ISSN 0104-4230. Disponível em:< http://www.scielo.br/pdf/ramb/v59n5/v59n5a12.pdf> Acesso em 26 set. 2014.

6. SONIS, S. T. et al., Perspectives on cancer therapy-induced mucosal injury: pathogenesis, measurement, epidemiology, and consequences for patients. Cancer, v. 100, n.9, p.19952025, 2004. Disponível em: http://onlinelibrary.wiley.com/doi/10.1002/cncr.20162/pdf>. Acesso em 22 out. 2014.

7. SANTOS, R. C. S. et al. Mucosite em pacientes portadores de câncer de cabeça e pescoço submetidos à radioquimioterapia. Rev. esc. enferm. USP [online], v.45, n.6, p. 1338-1344, 2011. ISSN 0080-6234. Disponível em: http://www.scielo.br/pdf/reeusp/v45n6/v45n6a09.pdf> Acesso em 26 set 2014.

8. SCHIRMER, E. M.; FERRARI, A.; TRINDADE, L. C. T. Evolução da mucosite oral após intervenção nutricional em pacientes oncológicos no serviço de cuidados paliativos. Rev. dor [online], $\quad$ v.13, n.2, p. 141-146, 2012. ISSN 1806-0013. http://www.scielo.br/pdf/rdor/v13n2/09.pdf>. Acesso em 26 set 2014. 